\title{
Physiological adaptation and gene expression analysis of Casuarina equisetifolia under salt stress
}

\author{
C. FAN, Z. QIU, B. ZENG*, X. LI, and S.H. XU \\ Research Institute of Tropical Forestry, Chinese Academy of Forestry, Guangzhou 510520, P.R. China
}

\begin{abstract}
Casuarina equisetifolia is widely planted in coastal areas of tropical and subtropical regions as windbreaks or to stabilize dunes against wind erosion due to its high salt tolerance and nitrogen-fixing ability. To investigate the mechanisms responsible for its salt tolerance, we examined growth, mineral composition, expression of genes for sodium $\left(\mathrm{Na}^{+}\right)$and potassium $\left(\mathrm{K}^{+}\right)$transport proteins, and antioxidant responses under $\mathrm{NaCl}$ treatments. Increasing $\mathrm{NaCl}$ concentrations inhibited lateral root elongation and decreased plant height, length of internodes, and numbers of branches and twigs. The $\mathrm{Na}^{+}$content significantly increased whereas the $\mathrm{K}^{+}$content significantly decreased in both shoots and roots with increasing external $\mathrm{NaCl}$ concentration, resulting in a significant increase in $\mathrm{Na}^{+} / \mathrm{K}^{+}$ratio. $\mathrm{Most}$ of the $\mathrm{Na}^{+} / \mathrm{H}^{+}$antiporter genes $(N H X \mathrm{~s})$ were obviously upregulated in roots after 24 and $168 \mathrm{~h}$ of salt stress, and $N H X 7$ was especially induced after $168 \mathrm{~h}$. Almost all salt overly sensitive $(S O S)$ genes were induced after 168-h treatment. Additionally, activities of superoxide dismutase, glutathione peroxidase, and catalase were significantly changed in shoots and roots under salt stress. Hence, we conclude that salinity tolerance of $C$. equisetifolia mainly relied on sequestering excess $\mathrm{Na}^{+}$into vacuoles and on induced expression of $N H X$ and $S O S$ genes in roots and thus the maintenance of sufficient $\mathrm{K}^{+}$content in shoots.
\end{abstract}

Additional key words: antiporter genes, catalase, glutathione peroxidase, ion homeostasis, potassium, salt overly sensitive, sodium, superoxide dismutase.

\section{Introduction}

Salt stress is one of the most serious abiotic stresses worldwide. It causes osmotic stress, ionic toxicity, and nutritional imbalances, and even leads to plant death (Türkan and Demiral 2009). However, some plants like halophytes and semi-halophytes can grow at high salinity due to sequestering salts in cell vacuoles, synthesizing compatible solutes, and possessing a complex antioxidant defence systems (Zhu 2003). Discovering the mechanisms of salt stress tolerance and conferring them to crops and other economically important sensitive plants is desirable for sustainable food and wood production. Many studies have focused on elucidation of physiological, biochemical, and molecular mechanisms of ion exclusion, osmotic adjustment, and defence against oxidative stress in salinity-tolerant species (Munns and Tester 2008). Many genes including those related to osmolyte synthesis or accumulation, signalling pathways regulation, oxidative protection, and regulating ion homeostasis have been recognized (Munns and Tester 2008, Yang et al. 2009). Among them, salt overly sensitive (SOS) pathway proteins and $\mathrm{Na}^{+} / \mathrm{H}^{+}$antiporters (NHX) were identified as the key to responses to salt stress by restricting the accumulation of toxic $\mathrm{Na}^{+}$.

Casuarina equisetifolia of the family Casuarinaceae is extensively cultivated in coastal areas and on limestone soils near the shore of tropical and subtropical regions for sand stabilization, soil rehabilitation, and as shelterbelts. Thus, C. equisetifolia performed important ecosystem

Submitted 1 August 2017, last revision 26 January 2018, accepted 1 February 2018.

Abbreviations: Car - carotenoids; CAT - catalase; Chl - chlorophyll; d.m. - dry mass; EC - electrical conductivity; f.m. - fresh mass; GR - glutathione reductase; GSH-Px - glutathione peroxidase; MDA - malondialdehyde; $\mathrm{NHX}-\mathrm{Na}^{+} / \mathrm{H}^{+}$antiporters; POD peroxidase; qPCR - quantitative PCR; SOD - superoxide dismutase; SOS - salt overly sensitive; WC - water content.

Acknowledgments: We are grateful to the Ministry of Science and Technology of China (2013AA102705) and the Fundamental Research Funds for Central Public Welfare Research Institute (RITFYWZX201304) for financial support. We are also grateful to Dr. Zhang Yong for providing experimental materials.

* Corresponding author; e-mail: 27964930@qq.com 
and coastal forests have recently gained great recognition, particularly after the devastating Southeast Asian tsunami (De Zoysa 2008). It is also an excellent raw material for the paper and pulp industries and it is preferred for use as poles and in scaffoldings (Zhong et al. 2010). As highly tolerant to salinity stress and being a non-halophyte, there is particular interest in study how this species responds and adapts to salinity stress. Recently, some clones of C. equisetifolia with high salt-tolerance were selected on basis of proline content, electrical conductivity (EC), peroxidase (POD) activity, and seed germination under salt stress (Yong et al. 2008, Wu et al. 2010). It was reported that $C$. equisetifolia seedlings could survive in $500 \mathrm{mM} \mathrm{NaCl}$ solution and proline was thought to be a major compatible solute to adjust osmotic pressure (Tani and Sasakawa 2003). Recently, several genes were identified in responses to cold stress and nitrogen fixation in C. equisetifolia (Obertello et al. 2007, Péret

\section{Materials and methods}

Plants and treatments: Seedlings of Casuarina equisetifolia L. clone A8 were cultured in a growth chamber of the Research Institute of Tropical Forestry for 8 weeks. For treatment with different $\mathrm{NaCl}$ concentrations, the plants were transferred to turf soil. After 1 week, plants were irrigated every $2 \mathrm{~d}$ with $0,200,400$, or $600 \mathrm{mM} \mathrm{NaCl}$ solution and grown under a 16-h photoperiod, an irradiance of $200 \mu \mathrm{mol} \mathrm{m} \mathrm{m}^{-2} \mathrm{~s}^{-1}$, day/night temperatures of $24 / 18{ }^{\circ} \mathrm{C}$, and a relative humidity of $70 \%$ for 4 weeks. To test various durations of salt treatment, the roots of control plants were washed with clean water, and then the plants were treated with $1 / 2$ Hoagland solution containing $200 \mathrm{mM} \mathrm{NaCl}$ for $0,1,6$, 24 , and $168 \mathrm{~h}$. The roots and shoots were harvested and stored at $-80{ }^{\circ} \mathrm{C}$ until analyses.

Growth, water content, $\mathrm{Na}^{+}$and $\mathrm{K}^{+}$content, and photosynthetic pigments: After different treatments, plant fresh mass (f.m.), shoot height, and basal stem diameter were recorded. Dry mass (d.m.) was determined after oven drying at $60{ }^{\circ} \mathrm{C}$ for $72 \mathrm{~h}$, when constant mass was reached. The water content (WC) [\%] was calculated as [(f.m. - d.m. $) /$ f.m. $] \times 100$.

To determine $\mathrm{Na}^{+}$and $\mathrm{K}^{+}$content, samples were finely ground, and then digested with concentrated $\mathrm{HNO}_{3}$ in a microwave system CEM Mars 5 (Matthews, NC, USA). The extracts were analyzed using inductively coupled plasma optical emission spectroscopy (ICP-OES) (Varian Vista-PRO RL, Palo Alto, CA, USA).

Chlorophyll (Chl) $a, \mathrm{Chl} b$, and carotenoids (Car) content was determined after extraction of fresh leaf tissue in $95 \%(\mathrm{v} / \mathrm{v})$ ethanol in darkness. The absorbance was measured with a UV-visible spectrophotometer (UV2450, Shimadzu, Kyoto, Japan) at 665, 649, and 470 nm. Quantities of Chl $a, \mathrm{Chl} b$, and Car in the extracts et al. 2007, Li et al. 2016). However, few studies in this species have focused on ion toxicity and scavenging ROS in response and during adaptation to salinity, and no study has investigated molecular mechanisms and expression patterns of related genes mediating its adaptation to salinity stress.

For these reasons, $\mathrm{Na}^{+}$and $\mathrm{K}^{+}$content and activities of antioxidant enzymes superoxide dismutase (SOD, EC 1.15.1.1), catalase (CAT, EC 1.11.1.6), peroxidase (POD, EC 1.11.1.7), glutathione peroxidase (GSH-Px, EC 1.11.1.9), and glutathione reductase (GR, EC 1.6.4.2) were determined under different $\mathrm{NaCl}$ concentrations and treatment durations. Additionally, transcript analyses of the HKT1, NHXs, and SOS genes in roots were performed. The aim was to explore the effects of salinity on $C$. equisetifolia and to identify likely critical mechanisms in adaptation to high salinity such as osmotolerance or specific ion toxicity.

were calculated using the following formulae: Chl $a=$ $\left(13.95 \times \mathrm{A}_{665}\right)-\left(6.88 \times \mathrm{A}_{649}\right), \mathrm{Chl} b=\left(24.96 \times \mathrm{A}_{649}\right)-$ $\left(7.32 \times \mathrm{A}_{665}\right)$, and $\mathrm{Car}=\left[\mathrm{A}_{470} \times 1000-(2.05 \times \mathrm{Chl} a)-\right.$ $(11.48 \times \mathrm{Chl} b)] / 245$.

\section{Antioxidant enzymes assay and malondialdehyde (MDA) content}

To extract antioxidant enzymes, fresh shoot and root samples $(0.1 \mathrm{~g})$ were ground into a fine powder with liquid nitrogen, and then were homogenized in $0.9 \mathrm{~cm}^{3}$ of ice-cold $10 \mathrm{mM}$ phosphate buffer ( $\mathrm{pH}$ 7.4). The homogenate was centrifuged at $12000 \mathrm{~g}$ and $4{ }^{\circ} \mathrm{C}$ for $15 \mathrm{~min}$, and the supernatants were used for determination of the activities of $\mathrm{Cu}-\mathrm{Zn}$ SOD (which represents about $90 \%$ of total SOD), CAT, POD, GSH-Px, and GR using assay kits (Nanjing Jiancheng Bioengineering Institute, Nanjing, China). All enzymes were detected with UV-Vis spectrophotometer and their activities were expressed as $\mathrm{U} \mathrm{g}^{-1}$ (f.m.). One unit of SOD was defined as the amount of enzyme that inhibits $50 \%$ nitroblue tetrazolium photoreduction. One unit of CAT or POD was calculated as the enzyme activity that decomposed $1 \mu \mathrm{mol}$ of $\mathrm{H}_{2} \mathrm{O}_{2}$ per minute. One unit of GSH-Px was defined as the enzyme activity that oxidizes $1 \mu \mathrm{mol}$ of NADPH per minute. One unit of GR was defined as the enzyme activity that reduced $1 \mu \mathrm{mol}$ of GSSG per minute.

Malondialdehyde (MDA) content was measured using MDA determination kit (Nanjing Jiancheng Bioengineering Institute) according to the manufacturer's instructions. Briefly, the shoot and root homogenates were centrifuged at $12000 \mathrm{~g}$ and $4{ }^{\circ} \mathrm{C}$ for $15 \mathrm{~min}$, and the supernatants were collected. The MDA and thiobarbituric acid (TBA) mixture was produced during the reaction of MDA in samples with TBA, and then this mixture was measured at $535 \mathrm{~nm}$. 
RNA extraction, cDNA synthesis, and real-time PCR: Total RNA from each sample was isolated separately using the RN38 EASYspin plus Plant RNA kit (Aidlab Biotech, Beijing, China) following the manufacturer's instructions. RNA samples were treated with the RNaseFree DNaseI (Qiagen, Valencia, CA, USA) to eliminate residual genomic DNA. The purified RNA was quantified with a NanoDrop 2000 spectrophotometer (Thermo Fisher Scientific, Wilmington, DE, USA) and RNA integrity was evaluated with an Agilent 2100 Bioanalyzer (Agilent Technologies, Santa Clara, CA, USA). Next, for each sample, $2.0 \mu \mathrm{g}$ of total RNA was used as a template in cDNA synthesis with the SuperScriptIII reverse transcriptase (Invitrogen, Carlsbad, CA, USA) and cDNA products were diluted 25 -fold for real time quantitative (q) PCR.

The sequences of HKT1, NHX, and SOS genes were obtained from the assembly of $C$. equisetifolia root transcriptome sequenced using Illumina HiSeq technology (SRP064226 in NCBI SRA). The gene primers were designed using the Primer 3 software (http:// www.genome.wi.mit.edu/cgi-bin/primer/primer3.cgi). The gene names, sequences, and primers used for real-time qPCR analysis are listed in Table 1. The real-time qPCR was performed on an Applied Biosystems 7500 using SYBR Premix Ex Taq ${ }^{\mathrm{TM}}$ kit (TaKaRa, Shiga, Japan) following the manufacturer's instructions. Thermal cycling conditions were: $95{ }^{\circ} \mathrm{C}$ for $30 \mathrm{~s}$ followed by 40 cycles at $95{ }^{\circ} \mathrm{C}$ for $5 \mathrm{~s}$ and at $60{ }^{\circ} \mathrm{C}$ for $34 \mathrm{~s}$. The dissociation curve was obtained by heating the amplicon from 60 to $95{ }^{\circ} \mathrm{C}$. The CaeUBC and CaeEFla combination was used as an internal control (Fan et al. 2017). Each sample was analyzed three times. The relative expression was calculated by $\Delta \Delta \mathrm{CT}$ method (Livak and Schmittgen 2001). Meanwhile, non-template controls and RT negative control were used for each sample.

Statistical analysis: All experiments were repeated at least three times, and data were analyzed by one-way ANOVA using IBM SPSS Statistics 19 for Windows (IBM, Armonk, NY, USA). Means were compared using the least significant difference (LSD) test at $P<0.05$. To explore patterns of changes of different traits and gene expression, all data sets were normalized using Z-score transformation, and then clustered based on Euclidean distance. The heat maps were generated by using MultiExperiment Viewer software (http://www.tm4. org/mev.html).

\section{Results}

Increasing concentrations of $\mathrm{NaCl}$ produced obvious growth inhibition of $C$. equisetifolia plants. In comparison with control plants, shoot length was significantly decreased by $16.3,24.4$, and $23.1 \%$ at 200 , 400 , and $600 \mathrm{mM} \mathrm{NaCl}$, respectively (Table 1). However, shoot diameter showed no significant changes. After treatment with 200 and $400 \mathrm{mM} \mathrm{NaCl}$ for 4 weeks, the decrease in length of internodes, branches, and twigs was parallel to a reduction in the numbers of branches and twigs; however, no other visible symptoms of toxicity were observed (Fig. 1 Suppl.). Additionally, the decrease in root growth was also characterized by a reduction in numbers of lateral roots. The effect of high $\mathrm{NaCl}$ concentration of $600 \mathrm{mM}$ resulted in considerable damage to plants, which were etiolated and had wilted leaves and black and decayed roots. For this reason, antioxidant enzyme activities in roots were not measured at this concentration and $600 \mathrm{mM} \mathrm{NaCl}$ might be the highest concentration partially tolerated by this species.

The water content in shoots and roots was affected by $\mathrm{NaCl}$ treatment. The $\mathrm{WC}$ in roots significantly and progressively decreased with increasing $\mathrm{NaCl}$ concentrations. The $\mathrm{WC}$ in roots decreased to approximately $20 \%$ when treated with $600 \mathrm{mM} \mathrm{NaCl}$, and control roots had WC of $65.6 \%$ whereas WC of control shoots was $86.8 \%$ (Table 1). Besides, Chl $a$, Chl $b$, and Car content was not significantly reduced at 200 and $400 \mathrm{mM} \mathrm{NaCl}$ but decreased dramatically at $600 \mathrm{mM} \mathrm{NaCl}$ (Table 1).

The $\mathrm{Na}^{+}$content increased in both shoots and roots with increasing salinity and reached 17.6 and 16.0 $\mathrm{mg} \mathrm{g}^{-1}$ (d.m.), respectively, in plants exposed to $600 \mathrm{mM}$ $\mathrm{NaCl}$ (Fig. $1 A, B$ ). The $\mathrm{K}^{+}$content slightly decreased in both shoots and roots at 200 and $400 \mathrm{mM} \mathrm{NaCl}$, but severely decreased at $600 \mathrm{mM} \mathrm{NaCl}$ (Fig. $1 A, B$ ). Thus,

Table 1. Characteristics of $C$. equisetifolia plants grown at various salinity. Means $\pm \mathrm{SEs}, n=3$, different letters indicate significant differences between treatments using the LSD test at $P<0.05$.

\begin{tabular}{|c|c|c|c|c|c|c|c|}
\hline \multirow{2}{*}{$\begin{array}{l}\mathrm{NaCl} \\
\text { conc. }[\mathrm{mM}]\end{array}$} & \multirow{2}{*}{$\begin{array}{l}\text { Shoot height } \\
{[\mathrm{cm}]}\end{array}$} & \multirow{2}{*}{$\begin{array}{l}\text { Shoot diameter } \\
{[\mathrm{mm}]}\end{array}$} & \multicolumn{2}{|c|}{ Water content $[\%]$} & \multicolumn{3}{|c|}{ Phytosynthetic pigments $\left[\mathrm{mg} \mathrm{g}^{-1}\right.$ (f.m.)] } \\
\hline & & & shoot & root & Chl $a$ & Chl $b$ & Car \\
\hline 0 & $47.89 \pm 3.81 \mathrm{a}$ & $2.87 \pm 0.26$ & $86.78 \pm 0.90 \mathrm{a}$ & $65.56 \pm 3.61 \mathrm{a}$ & $1.20 \pm 0.09 \mathrm{a}$ & $0.50 \pm 0.02 \mathrm{a}$ & $0.21 \pm 0.02 b$ \\
\hline 200 & $40.01 \pm 3.38 b$ & $3.07 \pm 0.38$ & $88.10 \pm 4.88 \mathrm{a}$ & $58.57 \pm 2.20 b$ & $1.30 \pm 0.04 \mathrm{a}$ & $0.54 \pm 0.02 \mathrm{a}$ & $0.23 \pm 0.006 \mathrm{ab}$ \\
\hline 400 & $36.20 \pm 2.83 b$ & $2.77 \pm 0.41$ & $83.42 \pm 2.53 \mathrm{ab}$ & $52.84 \pm 1.59 \mathrm{c}$ & $1.22 \pm 0.03 \mathrm{a}$ & $0.50 \pm 0.02 \mathrm{a}$ & $0.26 \pm 0.007 \mathrm{a}$ \\
\hline 600 & $36.86 \pm 5.25 b$ & $2.69 \pm 0.48$ & $78.65 \pm 0.93 b$ & $19.70 \pm 4.43 \mathrm{~d}$ & $0.53 \pm 0.04 b$ & $0.42 \pm 0.04 b$ & $0.08 \pm 0.01 \mathrm{c}$ \\
\hline
\end{tabular}


$\mathrm{Na}^{+} / \mathrm{K}^{+}$ratio in roots and shoots showed very significant increase with all $\mathrm{NaCl}$ concentrations compared with control plants (Fig. 1C). The highest $\mathrm{Na}^{+} / \mathrm{K}^{+}$was 3.269 and 7.503 in shoots and roots, respectively, which far exceeded 0.193 and 0.615 in controls. The $\mathrm{K}^{+}$shoot/root ratio showed no significant change under salt stress; and $\mathrm{Na}^{+}$shoot/root also showed no change when exposed to 200 and $400 \mathrm{mM} \mathrm{NaCl}$, but, at $600 \mathrm{mM} \mathrm{NaCl}$, there was a slight increase (Fig. 1D).

The $\mathrm{Na}^{+}$content in roots increased after $1 \mathrm{~h}$ of treatment and significantly increased with treatment time. The $\mathrm{K}^{+}$content decreased in roots after 24 and $168 \mathrm{~h}$ of $\mathrm{NaCl}$ treatment compared with controls (Fig. 2A). Also in shoots, $\mathrm{Na}^{+}$content increased during $168 \mathrm{~h}$ of salt treatment, however, $\mathrm{K}^{+}$content did not change (Fig. 2B).
The $\mathrm{Na}^{+} / \mathrm{K}^{+}$ratios clearly increased in roots and shoots with salt treatment time (Fig. $2 C$ ) and $\mathrm{Na}^{+} / \mathrm{K}^{+}$ratio was markedly higher in roots than in shoots (Fig. $2 C$ ). The $\mathrm{Na}^{+}$shoot/root ratio significantly decreased under salt treatment and $\mathrm{K}^{+}$shoot/root showed no change under less than $24 \mathrm{~h}$ of salt treatment (Fig. 2D). It was interesting that $\mathrm{K}^{+}$shoot/root ratio significantly increased when plants were exposed to $\mathrm{NaCl}$ solution for $168 \mathrm{~h}$ (Fig. 2D). Hence, we concluded that a high shoot cytosolic $\mathrm{K}^{+}$under salinity stress enabled maintaining enzymatic reactions, which is a characteristic feature of salt tolerance in C. equisetifolia. The $\mathrm{Na}^{+}$content was significantly higher in roots compared with shoots suggesting that C. equisetifolia could sequester $\mathrm{Na}^{+}$in root tissue to prevent sodium transfer to the shoot.
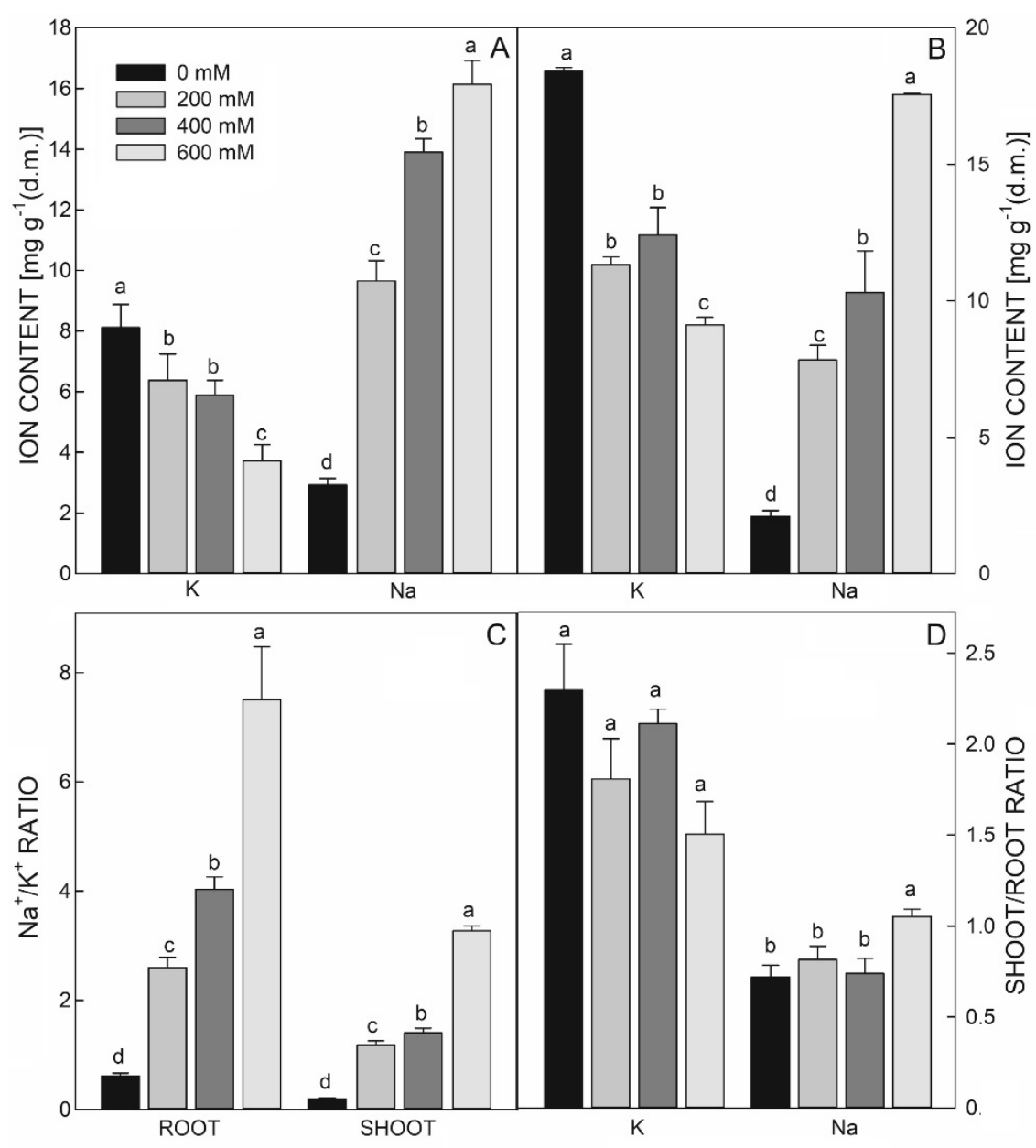

Fig. 1. Effects of various $\mathrm{NaCl}$ concentrations for $30 \mathrm{~d}$ on ion content in Casuarina equisetifolia. $A-\mathrm{Na}^{+}$and $\mathrm{K}^{+}$content in roots; $B-\mathrm{Na}^{+}$and $\mathrm{K}^{+}$content in shoots; $C-\mathrm{Na}^{+} / \mathrm{K}^{+}$ratio in shoots and roots; $\mathrm{D}$ - shoot/root ratio of $\mathrm{Na}^{+}$and $\mathrm{K}^{+}$. Means $\pm \mathrm{SEs}, n=3$, different letters indicate significant differences among treatments using the LSD test at $P<0.05$.

Activities of SOD, CAT, GR, GSH-PX, and POD in shoots and roots changed as a consequence of $\mathrm{NaCl}$ treatment. In comparison with control, SOD activity in shoots significantly increased only at $200 \mathrm{mM} \mathrm{NaCl}$ (Fig. 3A). GSH-PX and CAT activities significantly increased with increasing $\mathrm{NaCl}$ concentration with the exception of GSH-PX activity of shoots exposed to $600 \mathrm{mM} \mathrm{NaCl}$, for which there was a $65.7 \%$ reduction (Figs. $3 B$ and $4 B$ ). Interestingly, GR activity in shoots gradually declined with increasing $\mathrm{NaCl}$ concentrations 
(Fig. 3D), whereas POD activity did not change. In roots, GSH-PX and CAT activities significantly increased at $400 \mathrm{mM} \mathrm{NaCl}$, whereas POD activity significantly increased with all salt concentrations compared with the controls. However, $\mathrm{NaCl}$ treatment had no effect on SOD and GR activities in roots.

In shoots, $\mathrm{NaCl}$ induced higher SOD activity after $6 \mathrm{~h}$ of treatment compared with the control (Fig. 4A). The same trends was observed for GSH-PX, CAT, and POD activities (Fig. 4B,C,E). Under longer treatment duration, the SOD, GSH-PX, CAT, and POD activities decreased. However, GR activity in shoots showed no significant change after salt exposure (Fig. 4D). In roots, SOD and CAT activities remained unchanged after 1,6 , and $24 \mathrm{~h}$ of salt stress, but decreased significantly after $168 \mathrm{~h}$. The
GSH-PX and POD activities in roots decreased gradually with increasing duration of salt stress. Interestingly, GR activity in roots increased significantly after $1 \mathrm{~h}$ of salt stress compared with controls, however, after longer exposure, GR activity decreased to control level or less.

As an indicator of lipid peroxidation in plants under adverse environmental conditions, MDA content was altered by $\mathrm{NaCl}$ treatment. The MDA content significantly increased with $\mathrm{NaCl}$ treatments in shoots, but in roots, increases were only significant at 400 and $600 \mathrm{mM} \mathrm{NaCl}$ (Figs. $3 F$ and $4 F$ ). MDA content in shoots at $600 \mathrm{mM} \mathrm{NaCl}$ was more than three times higher than the control value. In response to short-term salt treatment, the MDA content did not change significantly in roots but significantly decreased in shoots.
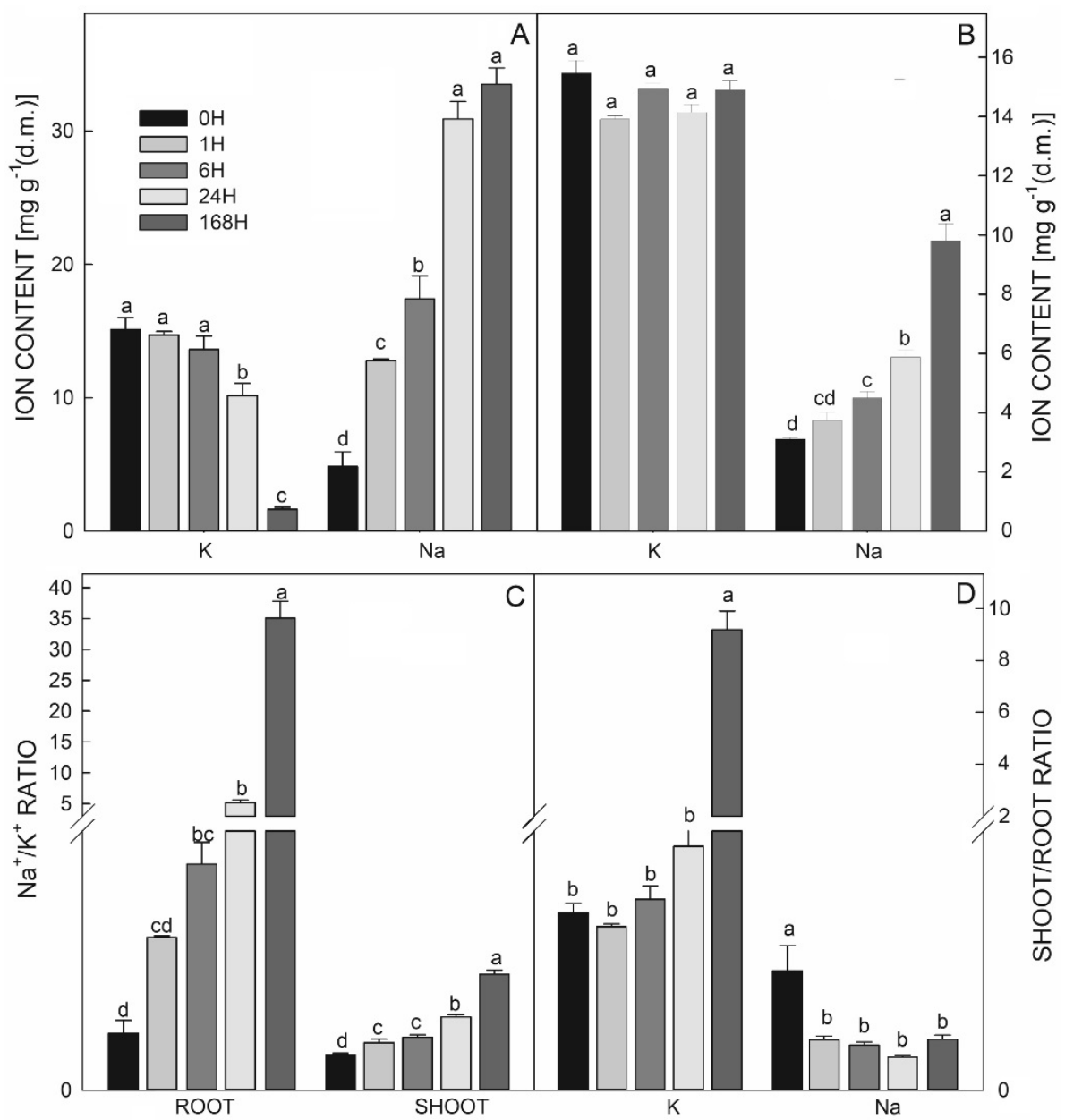

Fig. 2. Effect of different duration of $200 \mathrm{mM} \mathrm{NaCl}$ treatment on ion content in C. equisetifolia. $A-\mathrm{Na}^{+}$and $\mathrm{K}^{+}$content in roots; $B-\mathrm{Na}^{+}$and $\mathrm{K}^{+}$content in shoots; $\mathrm{C}-\mathrm{Na}^{+} / \mathrm{K}^{+}$ratio in shoots and roots; $\mathrm{D}$ - shoot/root ratio of $\mathrm{Na}^{+}$and $\mathrm{K}^{+}$. Means $\pm \mathrm{SEs}, n=3$, different letters indicate significant differences among treatments using the LSD test at $P<0.05$.

To determine the mechanisms underlying differential $\mathrm{Na}^{+}$and $\mathrm{K}^{+}$accumulation in C. equisetifolia, expression profiles of genes encoding $\mathrm{Na}^{+}$and $\mathrm{K}^{+}$transport proteins were analyzed in roots. CeqHKT1 and $N H X$ gene family members including CeqNHX1, CeqNHX2, CeqNHX3,
CeqNHX4, CeqNHX5, CeqNHX6, CeqNHX7/CeqSOS1, and $C e q N H X 8$ were annotated as $\mathrm{Na}^{+}$and $\mathrm{K}^{+}$transport related genes based on our previous transcriptomic sequencing for C. equisetifolia (SRP064226 in NCBI SRA, https://www.ncbi.nlm.nih.gov/sra/?term=SRP064226). 
These genes were strongly regulated under salt stress (Figs. 5,6). CeqNHX1, CeqNHX5, CeqNHX6, CeqNHX7, and CeqNHX8 were obviously upregulated with increasing time of salt treatment, but mRNA content of CeqNHX3 was reduced. It was interesting that CeqNHX1, CeqNHX7, and CeqNHX8 notably responded to salt stress and CeqNHX7 was only expressed at $168 \mathrm{~h}$ of salt treatment. However, CeqHKT1 and CeqNHX4 were slightly downregulated at $24 \mathrm{~h}$ of salt stress treatment and CeqNHX2 was downregulated at $1 \mathrm{~h}$. The SOS salt stress signalling pathway is central to ion homeostasis under salt stress and plays a pivotal regulatory function in salt tolerance (Zhu 2000). One SOS1 (NHX7), three SOS2, three SOS3, one SOS4, one SOS5 and four SOS6 genes were recognized in our previous transcriptomic sequencing for C. equisetifolia (SRP064226 in NCBI

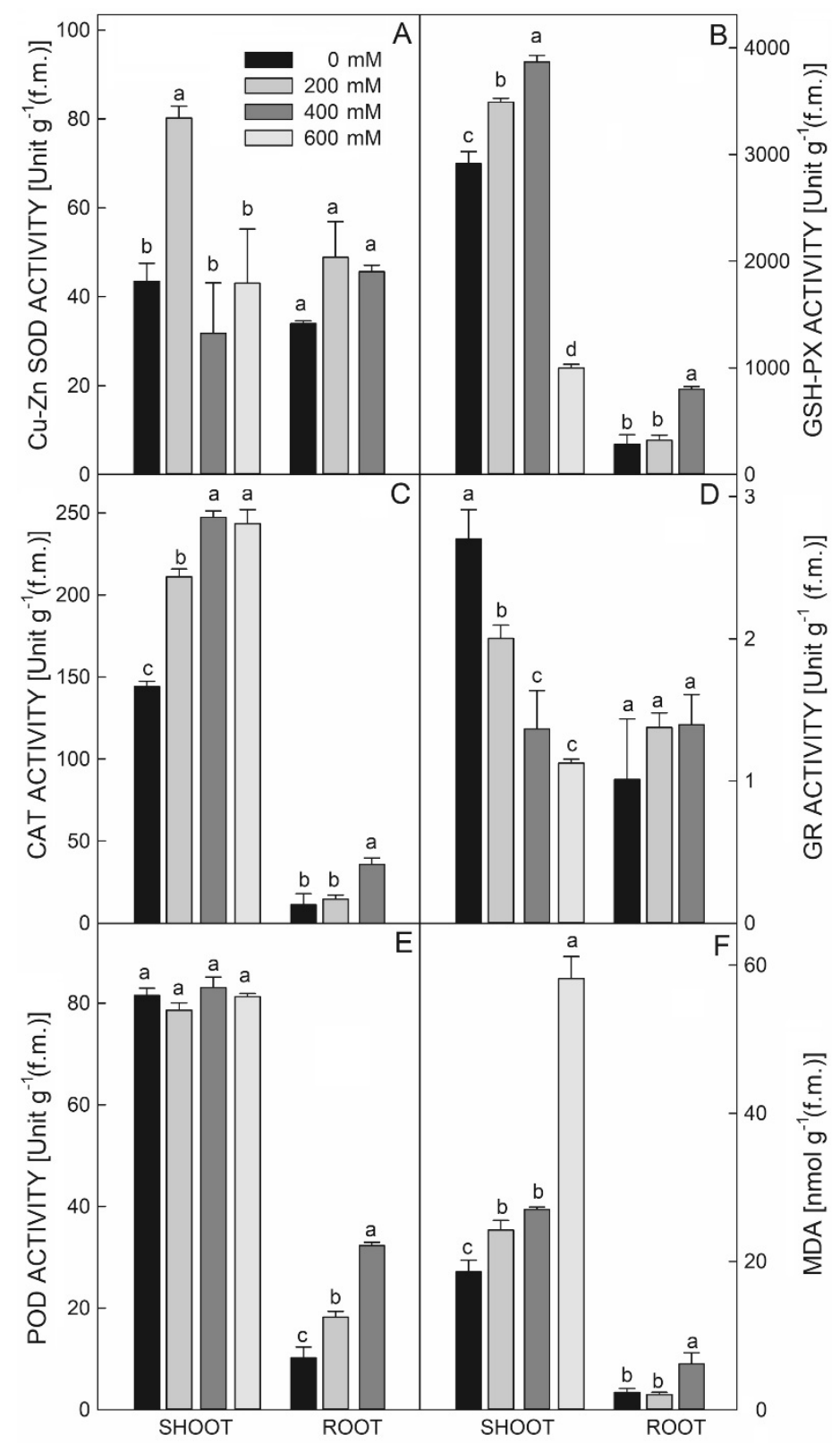

Fig. 3. Antioxidant enzyme activities and malondialdehyde (MDA) content in shoots and roots of C. equisetifolia subjected to NaCl treatments. Activities of $A$ - superoxide dismutase (SOD), $B$ - glutathione peroxidase (GSH-PX), $C$ - catalase (CAT), $D$ - glutathione reductase (GR), $E$ - peroxidase (POD), and $F$ - MDA content. Means \pm SEs, $n=3$, different letters indicate significant differences among treatments using the LSD test at $P<0.05$. 


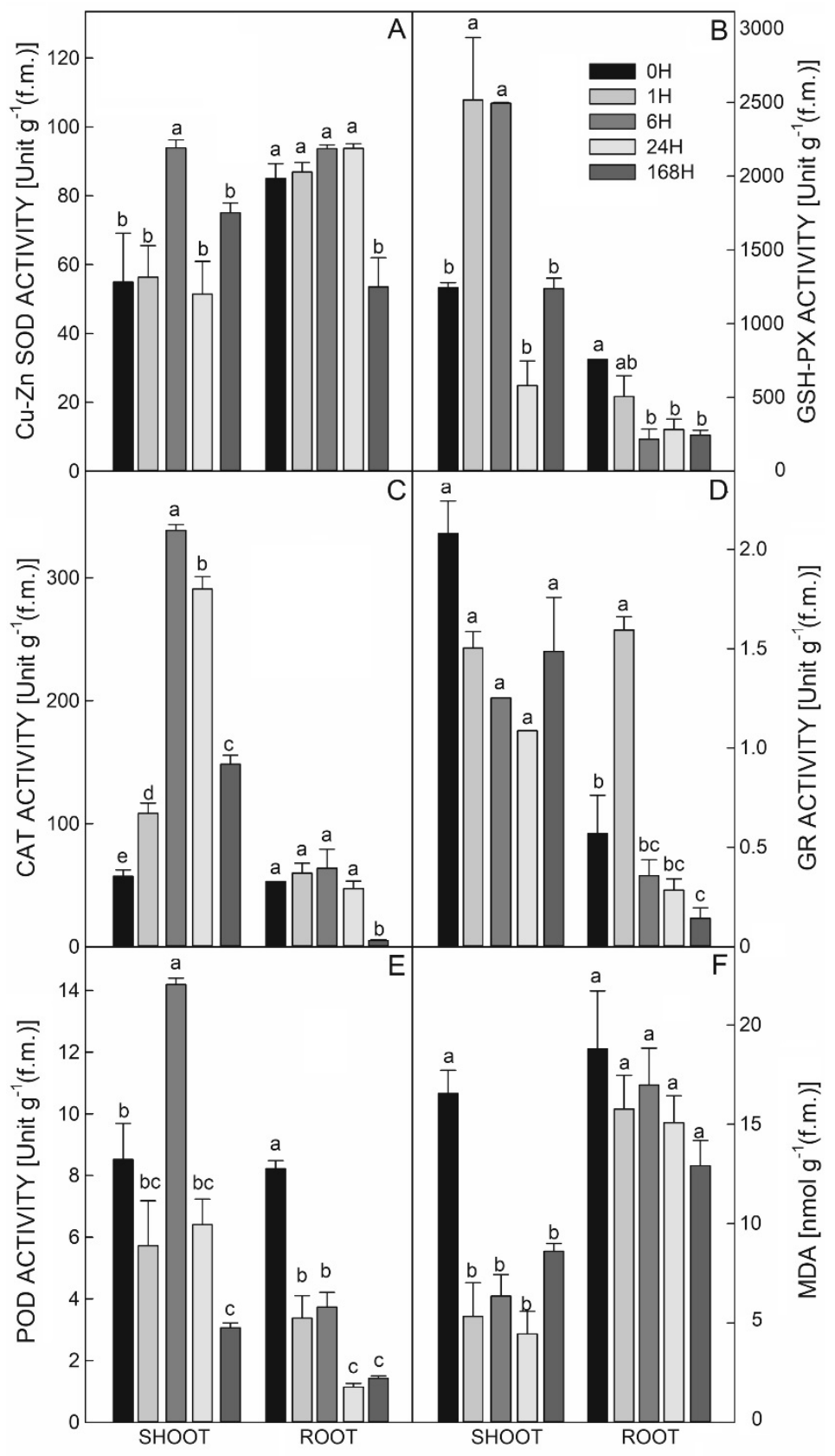

Fig. 4. Time course of antioxidant enzyme activities and MDA content in shoots and roots of $C$. equisetifolia grown under $200 \mathrm{mM}$ NaCl. $A$ - SOD, $B$ - GSH-PX, $C$ - CAT, $D$ - GR, $E$ - POD, $F$ - MDA. Means \pm SEs, $n=3$, different letters indicate significant differences among treatments using the LSD test at $P<0.05$.

$S R A)$. Thus, these genes were investigated here using real-time qPCR. In C. equisetifolia roots, expressions of almost all SOS genes were upregulated under salt treatment (Figs. 5 and 6). It was noteworthy that transcriptions of CeqNHX7, CeqSOS2.3, CeqSOS3.2, CeqSOS6.1 and CeqSOS6.3 were detected only when $\mathrm{NaCl}$ was applied. Notably, CeqNHX7, CeqSOS3.2, and CeqSOS6.3 were induced only at 24- or 168-h salt treatments.

The traits were clustered into two main groups (group A and group B), each with three sub-groups along different $\mathrm{NaCl}$ concentrations (Fig. 7). Overall, the values of traits in group A were greatly depressed by $\mathrm{NaCl}$ treatment. For example, $\mathrm{K}^{+}$content in shoots, seedling height, and GR activity in shoots clustered in sub-group A-1; stem diameter and SOD activity in shoot clustered in sub-group A-2; and water content in both shoots and roots, $\mathrm{K}^{+}$content in shoots, and $\mathrm{Chl} a$ and $\mathrm{Chl} b$ clustered in sub-group A-3. In contrast, the values of traits in group B were increased by $\mathrm{NaCl}$ treatment, especially MDA content and $\mathrm{Na}^{+}$content in shoots belonged to sub-group B-3 and reached the highest values at $600 \mathrm{mM} \mathrm{NaCl}$. 
Similarly, changes in traits and gene expressions during $\mathrm{NaCl}$ treatments were also clustered into two main groups (group $\mathrm{C}$ and group $\mathrm{D}$, Fig. $7 B$ ), with four and three sub-groups, respectively. Interestingly, in most subgroups, the traits were always clustered with expression of genes encoding $\mathrm{Na}^{+} / \mathrm{K}^{+}$transport proteins in roots. For example, the activities of GSH-PX, MDA, and POD in roots were clustered with expression of CeqNHX3 and CeqSOS5 in sub-group $\mathrm{C}-1$, but MDA activity and $\mathrm{K}^{+}$ content in shoots were clustered with expression of CeqHKT1 and CeqSOS6.3 in sub-group C-2. Similar observations were also found in sub-groups D-1, D-2, and D-3. For example, $\mathrm{Na}^{+}$content in roots was clustered

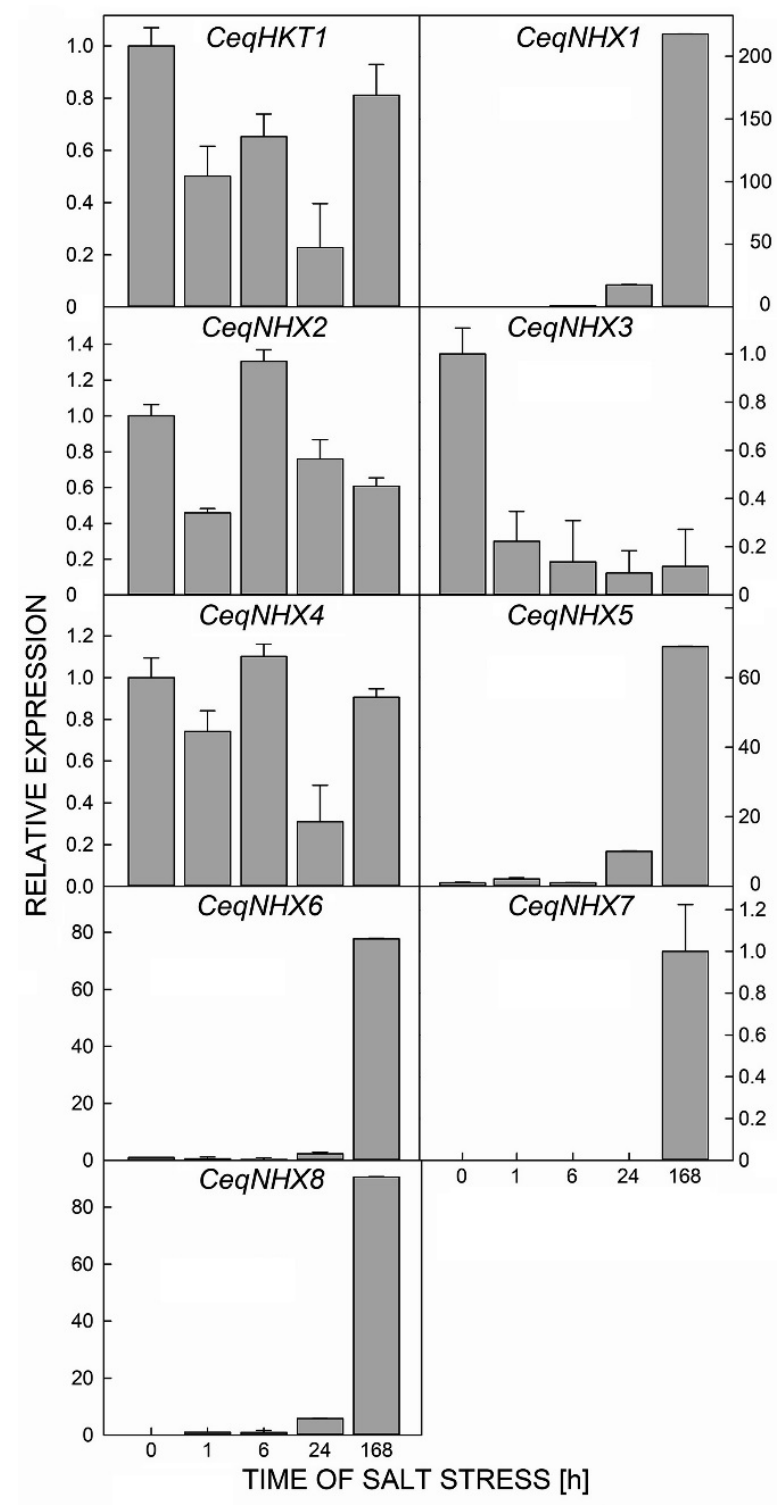

Fig. 5. Effect of different duration of $200 \mathrm{mM} \mathrm{NaCl}$ treatment on expressions of CeqHKT1 and CeqNHX genes in roots of C. equisetifolia. Means \pm SEs, $n=3$. with expression of CeqSOS3.3 and CeqSOS2.1 in subgroup D-2, and activities of SOD, CAT, and POD in shoots were clustered with expressions of CeqNHX4, CeqSOS2.2, and CeqNHX2 in sub-group D-3. These results indicated the contributions of these genes to the corresponding traits in shoots and roots under salt treatments. Together, the dynamic changes of traits and gene expression reflected a well-organized, coordinated, and complex regulation network in $C$. equisetifolia in response to salt stress.

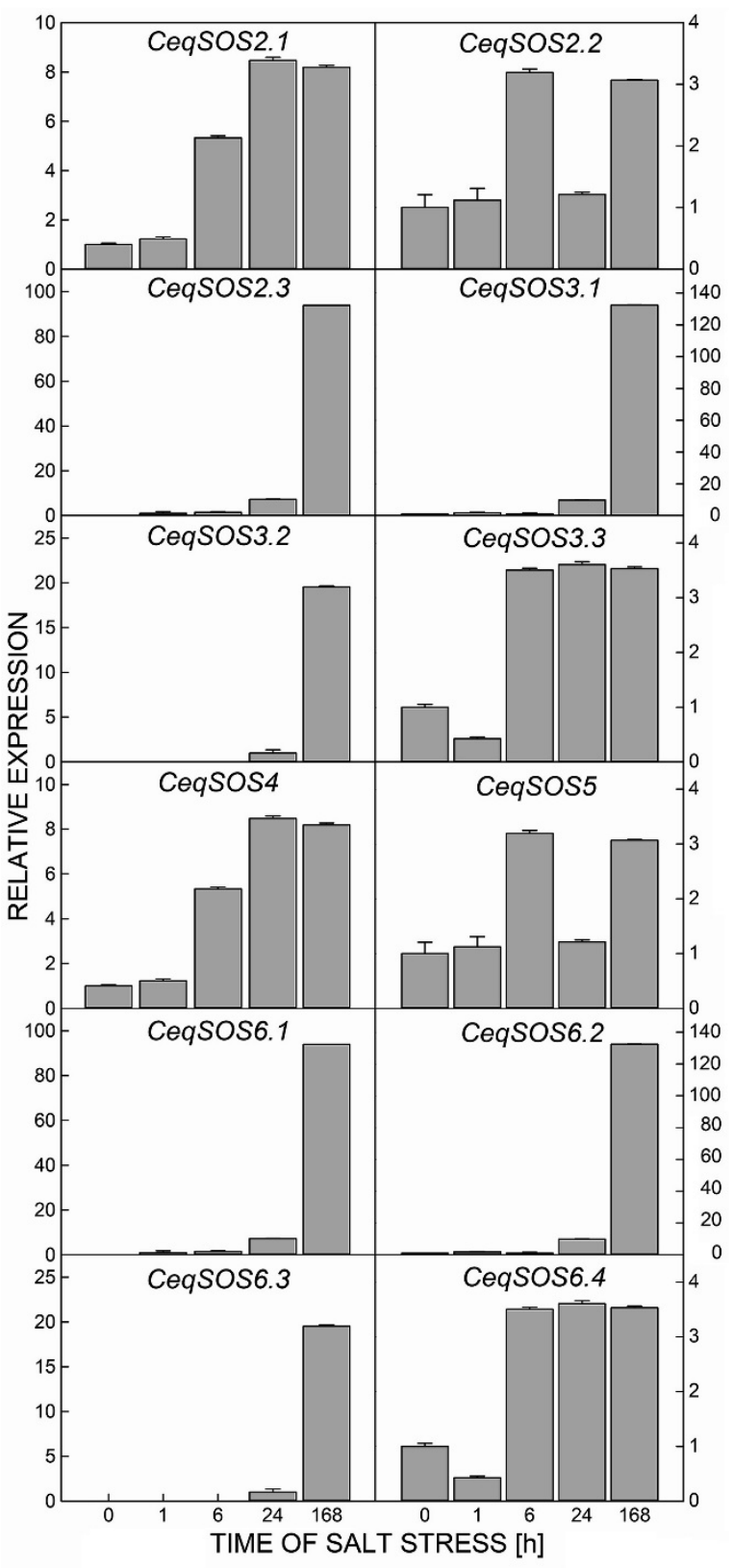

Fig. 6. Effect of different duration of $200 \mathrm{mM} \mathrm{NaCl}$ treatment on expressions of SOS genes in roots of $C$. equisetifolia. Means \pm SEs, $n=3$. 

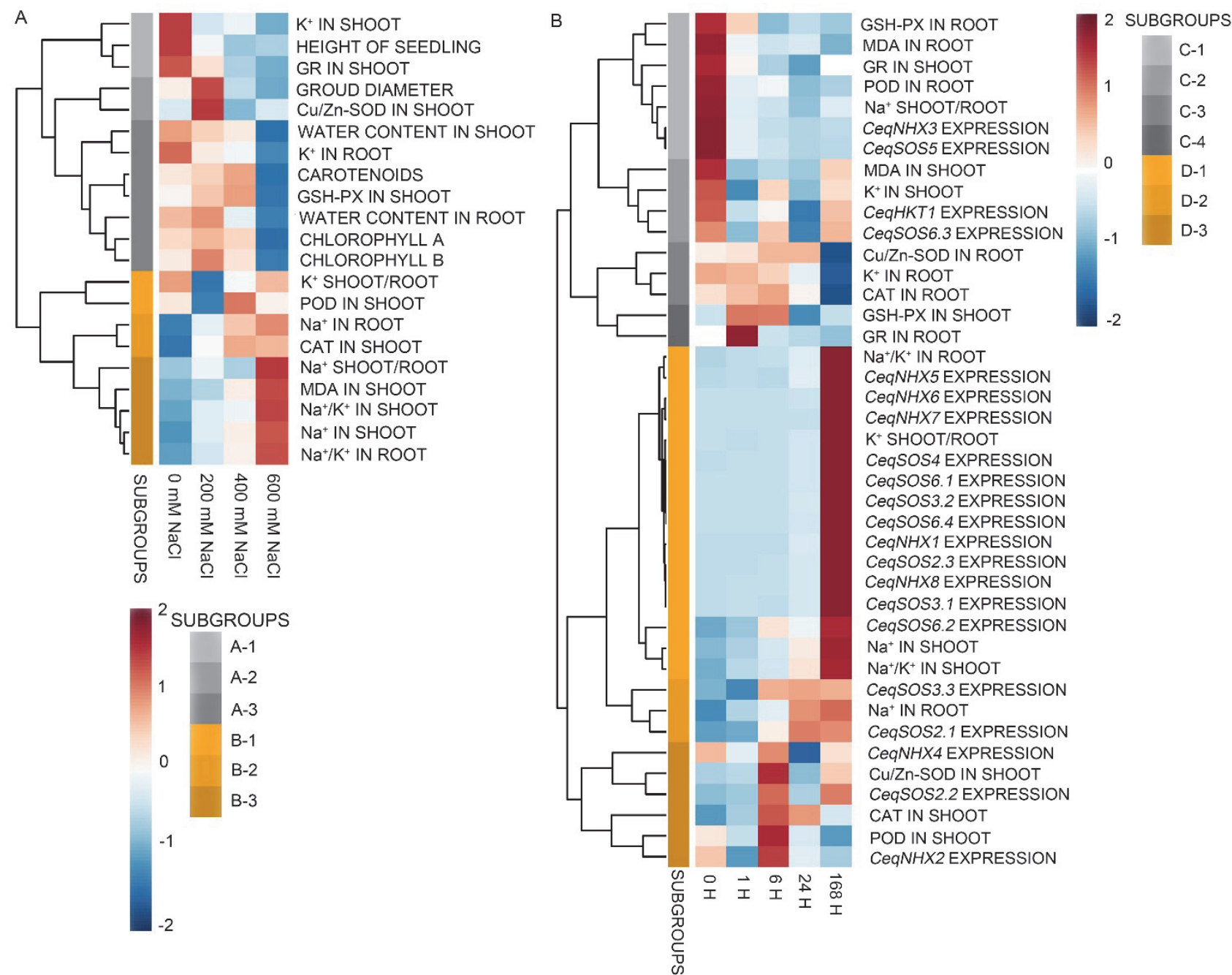

Fig. 7. Patterns of changes in different traits and gene expressions. $A$ - Patterns for different $\mathrm{NaCl}$ concentrations. $B$ - Patterns for different treatment duration. Values were normalized by Z-score transformation, and then clustered based on Euclidean distance. Different sub-groups are represented by different colours along the left side of the heatmap.

\section{Discussion}

As highly salt stress tolerant, $C$. equisetifolia was used in the present study to elucidate its adaptation to salinity stress using physiological and transcriptional analyses. Under $\mathrm{NaCl}$ stress, higher $\mathrm{Cu} / \mathrm{Zn}-\mathrm{SOD}$, GSH-PX, and CAT activities in roots and shoots, lower $\mathrm{Na}^{+}$content in shoots and lower $\mathrm{Na}^{+} / \mathrm{K}^{+}$ratios than in control were found. Salt stress increased the transcriptions of most NHXs and SOS genes.

Although no visual symptoms of $\mathrm{NaCl}$ toxicity were observed in $C$. equisetifolia shoots and roots when exposed to 200 and $400 \mathrm{mM} \mathrm{NaCl}$ solution, $\mathrm{NaCl}$ resulted in a significant reduction in their growth (fresh mass and number of branches and twigs). In Brassica juncea and Panicum miliaceum, the growth reduction under salt stress is connected with the inhibition of Chl biosynthesis and decreased $\mathrm{Chl} a$ and $\mathrm{Chl} b$ content
(Sabir et al. 2009, Mittal et al. 2012). It was surprising that Chl $a$ and $\mathrm{Chl} b$ content was almost unchanged in our treatments with 200 and $400 \mathrm{mM} \mathrm{NaCl}$. Hence, we speculated that $C$. equisetifolia plants tend to close stomata, subsequently leading to reduced photosynthesis and so plant growth. The roots were apparently damaged by $600 \mathrm{mM} \mathrm{NaCl}$ and the most affected were lateral roots. Our study suggests that salt stress inhibited plant growth by decreasing root growth and preventing formation and elongation of new twigs in $C$. equisetifolia.

At the biochemical level, antioxidant enzymes like SOD, CAT, POD, and GR play key roles in scavenging ROS produced in plant cells as byproducts of aerobic metabolism or as a result of disturbances in cell metabolic processes during salinity or other abiotic stresses (Apel and Hirt 2004). Recent studies show that CAT, SOD, GR, 
and APX activities are mostly up-regulated under salt stress (Y1ldiztugay et al. 2011, Mittal et al. 2012, Sekmen et al. 2012). In the present study, CAT and GSH-PX activities in shoots increased significantly with increasing $\mathrm{NaCl}$ concentration and duration of treatment. Parallel to our findings, significantly increased activities of CAT and GSH-PX were found in Suaeda salsa, Bruguiera gymnorrhiza, and 5-week-old tomato plants (Takemura et al. 2000, Caihong et al. 2005, Gapińska et al. 2008). Such results suggest that CAT and GSH-PX are key antioxidant enzymes acting synergistically in protecting cells against oxidative stress under salinity. The increase in SOD activity in shoots was observed after $6 \mathrm{~h}$ of $200 \mathrm{mM} \mathrm{NaCl}$ while SOD activity was not changed or decreased in other treatments. Hence, we conclude that SOD was essential at lower $\mathrm{NaCl}$ concentrations and during short periods for rapidly detoxifying superoxide anion in C. equisetifolia shoots. Similar results were also found in an endemic halophyte Centaurea tuzgoluensis under salt stress (Y1ldiztugay et al. 2011). Additionally, POD activity is essential in response to stress and significantly increases in tomato plants (Mittova et al. 2002, Chen and Heuer 2013), mulberry (Sudhakar et al. 2001) and alfalfa (Wang et al. 2009). In the present study, POD activity in roots of $C$. equisetifolia significantly increased with higher $\mathrm{NaCl}$ concentrations. However, POD activity in shoots did not significantly change with increasing $\mathrm{NaCl}$ concentration in accordance with results found in wheat (Perveen et al. 2011). Therefore, we suggest that POD probably contributed to a physical barrier against $\mathrm{NaCl}$ stress by participating in lignin biosynthesis, which also explained why POD activity did not significantly increase with higher $\mathrm{Na}^{+}$content in shoots.

The lower MDA content in shoots was observed in C. equisetifolia with increasing duration of salt stress, which also happens in cotton under low $\mathrm{NaCl}$ concentration (Meloni et al. 2003). We proposed that higher SOD, CAT, and GSH-PX activities rapidly detoxified ROS in $C$. equisetifolia shoots and then induced the lesser degree of membrane damage during short periods at lower $\mathrm{NaCl}$ concentrations.

Among salt-tolerant traits, the ability to restrict the transport and accumulation of $\mathrm{Na}^{+}$in shoots appears to be the most significant for adapting to salinity (Munns and Tester 2008). The C. equisetifolia plants accumulated

\section{Conclusions}

Salt stress in $C$. equisetifolia resulted in reduced shoot mass, shorter branches, and fewer twigs. Salinity induced several physiological and biochemical changes in $C$. equisetifolia, including small reduction in pigment contents, as well as decrease in $\mathrm{K}^{+}$content and increase in $\mathrm{Na}^{+}$accumulation and the $\mathrm{Na}^{+} / \mathrm{K}^{+}$ratio. The expression of all CeqSOS genes and CeqNHX1, CeqNHX5, CeqNHX6, more $\mathrm{Na}^{+}$in roots with increasing $\mathrm{NaCl}$ concentrations and time and plants showed rather low $\mathrm{Na}^{+}$content in shoots. Although $\mathrm{Na}^{+} / \mathrm{K}^{+}$in shoots and roots significantly increased with increasing $\mathrm{NaCl}$ concentrations and treatment duration, $C$. equisetifolia had still sufficiently high $\mathrm{K}^{+}$content. The observed reduction in growth was caused by increased $\mathrm{Na}^{+} / \mathrm{K}^{+}$ratio, but it was not lethal for C. equisetifolia. This is consistent with previous studies in barley and Gypsophila oblanceolata (Widodo et al. 2009, Sekmen et al. 2012). Many halophytic plants can accumulate inorganic ions to concentrations equal to or greater than those of the surrounding root solution to facilitate water uptake from the medium (Bradley and Morris 1991, Aghaleh et al. 2009). The accumulation of $\mathrm{Na}^{+}$in the root endodermis and exodermis is enabled by the deposition of apoplastic barriers, and thus $\mathrm{Na}^{+}$is prevented from direct entry with external fluid into the stele and so to the shoot (Krishnamurthy et al. 2011). However, excessive $\mathrm{Na}^{+}$often interferes with $\mathrm{K}^{+}$ accumulation, which results in impaired metabolic activities.

Various $\mathrm{Na}^{+}$transport proteins have been identified to restrict transport of $\mathrm{Na}^{+}$to shoots (Munns and Tester 2008). Among them, SOS pathway proteins and vacuolar NHX are considered as two efficient ways to reduce ion toxicity in plant cells by extrusion of $\mathrm{Na}^{+}$to the apoplast or external environment or sequestration of $\mathrm{Na}^{+}$in vacuoles (Munns and Tester 2008, Yang et al. 2009, Ji et al. 2013). To understand the mechanisms underlying limited $\mathrm{Na}^{+}$transport to the shoots in C. equisetifolia, we analyzed expressions of CeqHKT1, CeqNHX, and CeqSOS genes in this study. Expressions of all CeqSOS genes and CeqNHX1, CeqNHX5, CeqNHX6, CeqNHX7, and $C e q N H X 8$ genes in roots were upregulated under salt stress and expressions of most these genes was higher at 168-h salt treatment. This may be an important reason for the reduced shoot $\mathrm{Na}^{+}$content and salt damage. In previous studies, SOS signalling pathway activation was recognized as a key mechanism for $\mathrm{Na}^{+}$exclusion and ion homeostasis control (Zhu 2000, Ramezani et al. 2012, Feki et al. 2013, Zhao et al. 2016). The high expression of these genes at salt stress may be ascribed to signals originating from roots under salt stress, suggesting that C. equisetifolia roots could induce salt-tolerant genes to respond to salt stress.

CeqNHX7, and CeqNHX8 involved in $\mathrm{Na}^{+}$exclusion and ion homeostasis in roots were upregulated under salt stress. This may be important for high tolerance of $C$. equisetifolia to salinity stress. The salt tolerance of this species was also associated with increased activities of antioxidant enzymes CAT and GSH-PX. 


\section{References}

Aghaleh, M., Niknam, V., Ebrahimzadeh, H., Razavi, K.: Salt stress effects on growth, pigments, proteins and lipid peroxidation in Salicornia persica and S. europaea. - Biol. Plant. 53: 243-248, 2009.

Apel, K.,Hirt, H.: Reactive oxygen species: metabolism, oxidative stress, and signal transduction. - Annu. Rev. Plant Biol. 55: 373-399, 2004.

Bradley, P. M.,Morris, J. T.: Relative importance of ion exclusion, secretion and accumulation in Spartina alterniflora Loisel. - J. exp. Bot. 42: 1525-1532, 1991.

Caihong, P., Sujun, Z., Zhizhong, G.,Baoshan, W.: $\mathrm{NaCl}$ treatment markedly enhances $\mathrm{H}_{2} \mathrm{O}_{2}$-scavenging system in leaves of halophyte Suaeda salsa. - Physiol. Plant. 125: 490-499, 2005.

Chen, S., Heuer, B.: Effect of genotype and exogenous application of glycinebetaine on antioxidant enzyme activity in native gels of 7-day-old salt-stressed tomato (Solanum lycopersicum) seedlings. - Sci. Hort. 162: 106-116, 2013.

De Zoysa, M.: Casuarina coastal forest shelterbelts in Hambantota city, Sri Lanka: assessment of impacts. - Smallscale Forest. 7: 17-27, 2008

Fan, C., Qiu, Z., Zeng, B., Liu, Y., Li, X.,Guo, G.: Selection of reference genes for quantitative real-time PCR in Casuarina equisetifolia under salt stress. - Biol. Plant. 61: 463-472, 2017.

Feki, K., Quintero, F. J., Khoudi, H., Leidi, E. O., Masmoudi, K., Pardo, J. M.,Brini, F.: A constitutively active form of a durum wheat $\mathrm{Na}^{+} / \mathrm{H}^{+}$antiporter SOS1 confers high salt tolerance to transgenic Arabidopsis. - Plant Cell Rep. 33: 277-288, 2013.

Gapińska, M., Skłodowska, M.,Gabara, B.: Effect of short- and long-term salinity on the activities of antioxidative enzymes and lipid peroxidation in tomato roots. - Acta Physiol. Plant. 30: 11-18, 2008.

Ji, H., Pardo, J. M., Batelli, G., Van Oosten, M. J., Bressan, R. A.,Li, X.: The salt overly sensitive (SOS) pathway: established and emerging roles. - Mol. Plants 6: 275-286, 2013.

Krishnamurthy, P., Ranathunge, K., Nayak, S., Schreiber, L., Mathew, M. K.: Root apoplastic barriers block $\mathrm{Na}^{+}$ transport to shoots in rice (Oryza sativa L.). - J. exp. Bot. 62: 4215-4228, 2011.

Li, H., Li, N., Yang, S., Peng, H., Wang, L., Wang, Y., Zhang, X.,Gao, Z.: Transcriptomic analysis of Casuarina equisetifolia L. in responses to cold stress. - Tree Genet. Genomes 13: 7, 2016.

Livak, K. J., Schmittgen, T. D.: Analysis of relative gene expression data using real-time quantitative PCR and the $2^{-\Delta \Delta C T}$ method. - Methods 25: 402-408, 2001.

Meloni, D.A., Oliva, M.A., Martinez, C.A., Cambraia, J.: Photosynthesis and activity of superoxide dismutase, peroxidase and glutathione reductase in cotton under salt stress. - Environ. exp. Bot. 49: 69-76, 2003.

Mittal, S., Kumari, N.,Sharma, V.: Differential response of salt stress on Brassica juncea: photosynthetic performance, pigment, proline, D1 and antioxidant enzymes. - Plant Physiol. Biochem. 54: 17-26, 2012.

Mittova, V., Tal, M., Volokita, M.,Guy, M.: Salt stress induces up-regulation of an efficient chloroplast antioxidant system in the salt-tolerant wild tomato species Lycopersicon pennellii but not in the cultivated species. - Physiol. Plant.
115: 393-400, 2002.

Munns, R.,Tester, M.: Mechanisms of salinity tolerance. Annu. Rev. Plant Biol. 59: 651-681, 2008.

Obertello, M., Wall, L., Laplaze, L., Nicole, M., Auguy, F., Gherbi, H., Bogusz, D.,Franche, C.: Functional analysis of the metallothionein gene cgMT1 isolated from the actinorhizal tree Casuarina glauca. - Mol. Plant-Microbe Interact. 20: 1231-1240, 2007.

Péret, B., Swarup, R., Jansen, L., Devos, G., Auguy, F., Collin, M., Santi, C., Hocher, V., Franche, C., Bogusz, D., Bennett, M.,Laplaze, L.: Auxin influx activity is associated with Frankia infection during actinorhizal nodule formation in Casuarina glauca. - Plant Physiol. 144: 1852-1862, 2007.

Perveen, S., Shahbaz, M., Ashraf, M.: Modulation in activities of antioxidant enzymes in salt stressed and non-stressed wheat (Triticum aestivum L.) plants raised from seed treated with triacontanol. - Pak. J. Bot. 43: 2463-2468, 2011.

Ramezani, A., Niazi, A., Abolimoghadam, A.A., Zamani Babgohari, M., Deihimi, T., Ebrahimi, M., Akhtardanesh, H., Ebrahimie, E.: Quantitative expression analysis of TaSOS1 and TaSOS4 genes in cultivated and wild wheat plants under salt stress. - Mol. Biotech. 53: 189-197, 2012.

Sabir, P., Ashraf, M., Hussain, M., Jamil, A.: Relationship of photosynthetic pigments and water relations with salt tolerance of proso millet (Panicum miliaceum L.) accessions. - Pak. J. Bot. 41: 2957-2964, 2009.

Sekmen, A.H., Turkan, I., Tanyolac, Z.O., Ozfidan, C., Dinc, A.: Different antioxidant defense responses to salt stress during germination and vegetative stages of endemic halophyte Gypsophila oblanceolata Bark. - Environ. exp. Bot. 77: 63-76, 2012.

Sudhakar, C., Lakshmi, A.,Giridarakumar, S.: Changes in the antioxidant enzyme efficacy in two high yielding genotypes of mulberry (Morus alba L.) under $\mathrm{NaCl}$ salinity. - Plant Sci. 161: 613-619, 2001.

Takemura, T., Hanagata, N., Sugihara, K., Baba, S., Karube, I.,Dubinsky, Z.: Physiological and biochemical responses to salt stress in the mangrove, Bruguiera gymnorrhiza. Aquat. Bot. 68: 15-28, 2000.

Tani, C., Sasakawa, H.: Salt tolerance of Casuarina equisetifolia and FrankiaCeql strain isolated from the root nodules of C. equisetifolia. - Soil Sci. Plant Nutr. 49: 215222, 2003.

Türkan, I., Demiral, T.: Recent developments in understanding salinity tolerance. - Environ. exp. Bot. 67: 2-9, 2009.

Wang, W., Kim, Y., Lee, H., Kim, K., Deng, X.,Kwak, S.: Analysis of antioxidant enzyme activity during germination of alfalfa under salt and drought stresses. - Plant Physiol. Biochem. 47: 570-577, 2009.

Widodo, Patterson, J.H., Newbigin, E., Tester, M., Bacic, A., Roessner, U.: Metabolic responses to salt stress of barley (Hordeum vulgare L.) cultivars, Sahara and Clipper, which differ in salinity tolerance. - J. exp. Bot. 60: 4089-4103, 2009.

Wu, C., Zhang, Y., Tang, S., Zhong, C.: Effect of $\mathrm{NaCl}$ stress on Casuarina seed germination. - Seeds 4: 30-33, 2010.

Yang, Q., Chen, Z., Zhou, X., Yin, H., Li, X., Xin, X., Hong, X., Zhu, J., Gong, Z.: Overexpression of SOS (Salt Overly Sensitive) genes increases salt tolerance in transgenic Arabidopsis. - Mol. Plants 2: 22-31, 2009.

Yıldıztugay, E., Sekmen, A.H., Turkan, I., Kucukoduk, M.: 
Elucidation of physiological and biochemical mechanisms of an endemic halophyte Centaurea tuzgoluensis under salt stress. - Plant Physiol. Biochem. 49: 816-824, 2011.

Yong, Z., Chonglu, Z., Qingbin, J., Yu, C., Zhen, C.: Study on salt-tolerance ability in rooted cuttings of different Casuarina clones. - Forest Res. 21: 91-95, 2008.

Zhao, X., Wei, P., Liu, Z., Yu, B., Shi, H.: Soybean $\mathrm{Na}^{+} / \mathrm{H}^{+}$ antiporter GmsSOS1 enhances antioxidant enzyme activity and reduces $\mathrm{Na}^{+}$accumulation in Arabidopsis and yeast cells under salt stress. - Acta Physiol. Plant. 39:19, 2016.

Zhong, C., Zhang, Y., Chen, Y., Jiang, Q., Chen, Z., Liang, J., Pinyopusarerk, K., Franche, C., Bogusz, D.: Casuarina research and applications in China. - Symbiosis 50: 107114, 2010.

Zhu, J.: Genetic analysis of plant salt tolerance using Arabidopsis. - Plant Physiol. 124: 941-948, 2000.

Zhu, J.: Regulation of ion homeostasis under salt stress. - Curr. Opin. Plant Biol. 6: 441-445, 2003. 